\title{
Workarounds in the Danish Health Sector - from Tacit to Explicit Innovation'
}

\section{Katia Dupret ${ }^{2}$}

Associate Professor, Institute for People and Technology, Roskilde University, Denmark

\section{Bjarke Friborg}

Organizer/Analyst, PROSA (Danish Association of IT Professionals), Denmark

\begin{abstract}
Drawing on actor-network theory (ANT) and science and technology studies (STS) and on ethnographic research in Denmark, we argue that how health care workers work around technologies can be conceptualized as tacit innovation - that is, practical expressions of active encounters with the complexity of work situations and therefore potential sources of sustainable and innovative work practices. The concept 'invisible work' is used to show that 'what counts as work' is bound up with technologies that are not neutral. Technologies, professionals, and patients implicitly co-constitute innovation processes, and we argue that in order to understand the potential of tacit innovation among health care workers, one must revisit the dichotomy between technology producers and technology end-users. The aim and contribution of this paper is thus to attempt to revitalize the discussion about technology workarounds as initiatives of tacit innovation, thus adding to the theoretical conceptualization of invisible work when technologies are used in health care work.
\end{abstract}

\section{KEYWORDS}

Technology / invisible work / actor-network theory / employee-driven innovation / tacit innovation / health care

\section{Introduction}

he everyday work of an organization is interwoven with explicit and implicit dimensions, and both are necessary to constitute a work process. In practice, however, organizations commonly overestimate the importance and impact of the formally prescribed work process (the explicit dimension), while failing to acknowledge the actual performance of the tasks in that process and/or make them visible (Brown \& Duguid, 1991; Feldman \& Pentland, 2003). A number of studies show that creativity in implicit working processes mainly occurs unofficially and tacitly - as part of what happens 'behind the scenes' (Pols, 2006; Star \& Strauss, 1999) - and is therefore not highlighted in official job descriptions, which lie within what has here been called the explicit dimension (Barley \& Kunda, 2001; Hirschhorn, 1984).

\footnotetext{
${ }^{1}$ You can find this text and its DOI at https://tidsskrift.dk/njwls/index.

${ }^{2}$ Contact details for correspondence: Roskilde University, Universitetsvej 1, 4000 Roskilde, Denmark, katia@ruc.dk
} 
This paper discusses sources of innovation as being heterogenic and at times 'behind the scenes' - that is, invisible processes. The arguments for invisibility as a source of innovation are based on a theoretical reading in science and technology studies (STS) and actor-network theory (ANT) (e.g., Callon, 1986; Latour, 1996; Mol, 2002; Pols, 2005) and on fieldwork in the health care sector (Dupret, 2010, 2016; Dupret \& Hasse, 2012; Krogh, 2016). The concept of tacit innovation has been developed not only to conceptualize but also to acknowledge precisely these heterogenic and invisible processes. Thus, the concept is primarily a way of understanding innovative sources that can be - but are not necessarily - recognized and acknowledged as such in the outer organizational culture or by management. In making the argument that the added value inherent in these invisible processes qualifies them to be defined as 'innovative', this paper thus diverges from more traditional innovation studies, which 1) build on the classical definition developed by Schumpeter (1934), in which innovation is an effort by one or more individuals to generate economic profit through qualitative change, and/or 2) do not operate with an explicit understanding of innovative sources as heterogenic or potentially out of sight.

From an organizational perspective, it is argued that, because services in the health care sector are increasingly based on technological infrastructures and artefacts, sources of innovation thus need to be explored in relation to the complexity of the inter-professional practices that develop and sustain the health care of organization (Kyng, 2015). Hence, with a view to discussing the potential for making tacit innovation explicit, this paper not only focuses on the end-users of new technologies (i.e., health care workers) but also takes a look at the producers of these technologies as well as at the range of available methods and concepts specifically aimed at cross-disciplinary innovation sparked between health care staff and technology developers.

For staff working to develop and implement new technologies and IT systems, the challenge of harnessing the insight and innovative potential of everyday practitioners is a classic, well-researched issue. Certainly, IT can vastly improve data processing as well as simplify and streamline many work processes. However, the outcome can be quite different than intended, as demonstrated by indicators showing that $25 \%$ of all IT projects fail outright, $20-25 \%$ do not live up to their financial objectives, and up to $50 \%$ require 'material rework' in at least one area (IDC, 2009, quoted by Joseph Gulla, 2012). The responses to these failures have resulted in a variety of solutions and methodologies, from improved project management (PMI, 2017), more agile methodologies (Beck et al., 2001), and open source-inspired collaborative development models (Raymond, 1999) to employee-driven innovation (Høyrup, 2010), design thinking (Ferreira et al., 2015), and participatory design (Simonsen et al., 2015), recently supplemented with 'healthcare hackathons' specifically focused on health care (Silver et al., 2016). Although all of these responses are examples of distinct methodologies that are more or less theoretically and organizationally developed, they all circle around the explicit need to include diverse professional viewpoints in the early design and innovation stages and thus facilitate more sustainable solutions. In other words, the expectations posed to health care staff and IT staff - or the end-users and developers of technology, respectively - are both entrenched and different, a situation that requires an explanation. 


\section{Health care in Denmark - new tech demands to health care staff}

Although technologies have always been part of health care organizations and professions (Huniche \& Olesen, 2014), the complexity of technological infrastructure and the sheer number of artefacts is growing exponentially. One must take this development into account when speaking about the organizing principles and the professional life of health care staff in the Nordic countries today. Summed up by various concepts such as pervasive health care (PHC), technology-enabled care (TEC), connected health, point-ofcare (POC), etc., the health care sector in these countries is facing new paradigms based on home care and patient self-involvement enabled by telemedicine and medical equipment and supplies, such as beds and bandages with built-in processing capacity. These new paradigms are changing the lives of health care professionals, for which reason this fundamental redefinition of the health care sector's premises and tasks potentially challenges established hierarchies, job functions, and conventional divisions of labor.

In Denmark, formal as well as informal employee involvement is a distinct tradition, and workers and management traditionally collaborate, also through union representation in the hospital sector. In addition, interest in methods such as participatory design (Simonsen et al., 2015), collaborative innovation (Koivisto et al., 2015), employee-driven innovation (Høyrup, 2010), etc., is also widespread. All of these methods focus on the involvement and recognition of interdisciplinary insights, including a body of literature describing how to use these methods specifically in the development of health care IT (Kyng et al., 2008, 2012).

Remarkably, even in this Nordic context, employee dissatisfaction with overall relations between employees and top management remains an issue. Recurring themes include a perceived lack of employee involvement, disregard of professionalism, and top-down management relations, both in terms of technology specifically and work routines in general. These themes often spur confrontations with management paradigms such as New Public Management (NPM) and the demands it puts on productivity and measurability (Wiese, 2016). In other words, the hospital sector apparently remains fundamentally hierarchical and subject to management paradigms that more or less fit the particularities of the sector. On this background, the practice of workarounds among health care staff is not necessarily a sign of unilateral 'resistance to change', but could rather constitute action among groups notoriously skeptical of being managed by professional administrators rather than fellow professionals (Hjortshøj, 2016, p. 15).

Ash et al. (2004) define workarounds as 'clever methods for getting done what the system does not let you do easily’ (p. 195). This definition allows for the potentiality that professionals have a different work goal when doing their workarounds, and that this goal might, in fact, provide patients with better health care than the system makes possible. Further, Morath and Turnbull (2005) define workarounds as 'work patterns an individual or a group of individuals create to accomplish a crucial work goal within a system of dysfunctional work processes that prohibits the accomplishment of that goal or makes it difficult' (p. 52, in Halbesleben et al., 2008, p. 3-4). This definition even explicitly points out that workarounds are created to deal with 'dysfunctional work processes'.

These definitions pave the way for further discussing how normativity can be recognized in how one defines the ways that health care is innovated and the innovation that 
occurs within it. Halbesleben et al. (2008), for example, suggest that organizations are rarely capable of capturing the creative, professionally sound solutions that can result from workarounds. The paradigmatic idea of empowering patients, in other words, rarely seems to be mirrored by a similar approach to empowering and involving health care staff in the development of their own workplace.

This paper seeks to address this paradox and asymmetry, suggesting that we can develop more sustainable health care organizations by investigating the potentials of a cross-disciplinary collaboration between health care workers and IT developers - even if this is only one aspect of addressing a more or less dysfunctional work organization. Specifically, the paper notes a potential to be exploited in referring to IT development concepts for the purpose of highlighting and understanding the tacit innovation that health care staff already practice. In turn, this could make a contribution by crediting health care staff with their roles as innovative co-creators rather than merely end-users.

\section{Existing approaches to innovation and theoretical resources}

The literature on innovation within health care is diverse in both form and method (see review Dupret, 2010). It explores everything from different treatment technologies to the implementation of computer programs, personnel training, handling of databases, etc. Typically, this body of research reports on studies that have clear criteria for what is to be measured that is, the output. In these studies, the goals that define innovation and the measures of whether innovation has taken place are often linear, accumulative and causal, and focus primarily on the end-product. In this context, linear refers to time, accumulative means the work practices that in some way add to the productivity, efficiency, knowledge and value of the work, and causal means the frequent assumption that when work practices are influenced by, say, staff training in a new technology, the causal outcome will be more knowledge regarding the new technology.

However, the fieldwork drawn upon in this paper shows that innovation processes are often efforts that are unacknowledged or made invisible by the system prevalent in the workplace, or that are not recognized by management and must be constantly negotiated to gain a foothold. Thus, to understand the sources of innovation processes, one needs to acknowledge these, at times, invisible initiatives in order to gain knowledge about how they contribute to daily work practices.

The argument of this paper for acknowledging the invisible as innovative is inspired by the specificity of the mental health field and theoretically informed by readings of feminist thinkers within the STS and ANT fields (e.g., Haraway, 1991; Moser, 2003; Pols, 2006; Star, 1991; Star \& Strauss, 1999). ANT rejects any a priori separation of human and nonhuman, social, and technical elements (Alcadipani \& Hassard, 2010). It refers to the fact that the semiotic principle of meaning-making extends to materials (Greimas, 1987). Whether something can be changed and value added depends on far more than people's talk and actions (Callon, 1986; Latour, 2005, p. 116; Latour, 1993/1991; Latour \& Woolgar, 1986/1979). These changes in agency thus mean that the nonhuman aspect plays a co-constituting role in how we understand innovation processes. Further, feminist voices bring attention to potential asymmetrical changes in agency in relations between humans and technologies, thus raising questions as to the risk of reproducing an essentially 
hierarchical and managerial perspective that is likely to remain powerful when only the instrumental and linear aspects of sociotechnical relationships are in focus (Star, 1991).

In recent years in Denmark, greater attention is being given to how inter-professional collaboration, as well as rivalry, fundamentally characterizes health care organizations, with professional hierarchies and relations being constantly subject to renegotiation as well as reification (Krogh, 2016; Lehn-Christiansen, 2016). This may be one reason why contemporary health care staff are kept in roles primarily as end-users of technology (Silver et al., 2016) but also as public servants subjected to an organizational culture of zero-failure (Høyrup \& Andersen, 2012). Thus, they are discouraged from experimenting with and deviating from the official procedures because they fear the (negative) health consequences this might provoke. Conversely, software developers and other IT staff, that is, the quintessential technology producers with established norms about the value of innovation and 'hacking', are explicitly encouraged to engage in the creative pursuits of experimentation, workarounds, etc., whether for the sake of fun, problem-solving, or ethical considerations (Levy, 1984). In this perspective, the different expectations posed to the two groups stand out clearly, with the latter having distinctly more acknowledged room for innovative practices - a further indication that the innovative potential of health care workers is not fully acknowledged.

\section{(In-)visibility in work-life practices}

What becomes visible depends on the degree to which a specific activity is acknowledged as valuable and important to the organization (Pols, 2006). Here, Star and Strauss point to the importance of investigating the concrete practices of organizational life if one wants to discuss the ways in which work practices may be seen as marginalized or sustainable. In line with this thinking, technology workarounds raise questions as to what normativity staff refer to in order to make their work sustainable. Notably, Star (1991) stresses the importance of investigating the work performed around standardized practices. Using the example of the difficulties professionals at a fast-food chain have complying with a customer request, she argues that sociotechnical systems also depend on invisible ways of doing things that depart from the visible standard and are performed by other actors (both human and technical) in the network in order for the practice to be sustained.

The discussions of invisible versus visible work thus also have a material focus. 'What counts as work' is bound up with the technologies that are connected to a specific skill or specific knowledge (Star \& Strauss, 1999). It requires a lot of work to fit the entities or activities that do not easily fit into standardized work practices into the acknowledged/ visible practice. For example, as illustrated by Oudshoorn (2008), to portray telemedicine as a technology that increases efficacy presents problems because health care professionals and patients do a lot of work that ICT-mediated clinical encounters make invisible. The ideological inscription embedded in the technology often promises ease, simplicity, and efficiency. However, once in use, the sociotechnical setup just as often proves much more complex and demanding. For example, when interviewing staff, Oudshoorn found that some of the invisible work involved comforting and reassuring patients about their ability to master the new technology (p. 280), but these activities are encountered neither in the training in using the technology nor in the script of the technology itself. Likewise, Pols (2006) makes an invisible care practice in (mental) health care visible. The activity of 
washing the patient, she argues, is not considered an official focus of mental health care, but is performed as such in the daily practices that she has been investigating.

In the above-mentioned studies, health care professionals are invariably end-users of technologies, endeavoring to live up to certain formal and standardized expectations while still maintaining their professionalism. This not only gives rise to some clashes but also to new solutions, workarounds, and practices, both individual and collective.

Inspired by the focus on invisible practices and the role of technology, this paper looks out for specific entities and activities that may not be verbalized as innovative, but that indeed have an impact in the changing of work practices. Thus, the ambition of this paper is not to ask if the innovative efforts initiated on the part of management have been effective, but rather, as Berg and Mol (1998) suggest, to look for the unforeseen effects that result from introducing these new efforts. As Pols (2006, p. 427) and Dupret (2010) conclude, these types of approaches also enable analyses that make health care practices understandable without erasing troublesome situations or rendering them invisible. Developing the concept of tacit innovation and relating it to the practices applied by technology developers are thus also ways of grasping the invisible work.

\section{Why innovation and how?}

Although fairly new attempts have been made to systematically bring technological developers and health care professionals together, the question remains whether the problems and the practices focused on in these collaborative projects would, in fact, make the tacit innovations of health care professionals possible. In what ways do professionals' work practices allow tacit innovation to be acknowledged?

The health care professionals presented in the empirical examples below do not necessarily focus on stabilizing management-determined project initiatives in order to comply with the dominant paradigms, but rather to stabilize those initiatives by living up to their own professional ethics. For example, clinical evidence, monitoring tools, and diagnostic systems are increasingly prevalent in the health care sectors of Western societies (e.g., Rankin \& Campbell, 2006). The examples of tacit innovation presented in this paper, however, do not primarily aim to comply with new types of standardization and effectivity, but are rather calls for dialogue, reflection, bodily interaction, and alternative scientific standards.

The different examples illustrate that politics and managerial decisions greatly determine how new initiatives and practices are defined, but so does the professionalism of the professionals involved. All the professionals presented here are experienced senior staff, so are their judgments and commitment to changing their practices not to be taken seriously? Because their actions do not necessarily reproduce or follow institutional logic or managerial decisions regarding change, their initiatives remain invisible and tacit. So, innovation must also be discussed as a political practice.

\section{Ethnographic illustrations}

The empirical material generated for the analyses in this paper comes from two different health care specialities and three different change initiatives. There are two examples 
from the psychiatric field, one of which is conducted in a district psychiatric setting, where treatment is provided locally. Staff endeavor to treat patients in their own homes and thus prevent the need for hospitalization. ${ }^{1}$ These staff members make up an outreach adult psychiatric team (Dupret, 2010). The other example is taken from a study investigating how the new 'checkbox' electronic patient journal (EPJ) changed diagnostic practices in a psychiatric ward (Dupret, 2016). The third example is from a geriatric ward and investigates technological literacy among professionals (Hasse \& Brok, 2015). The observations of the psychiatric professionals were collected in 2005, and psychiatrists were interviewed in connection with a research project being prepared on how ethical dilemmas have changed in light of the new 'checkbox' EPJ. The observations and interviews done in the geriatric department were conducted in 2010. The empirical material used here is thus dispersed in terms of institutions, time, and varieties of professional situations.

\section{Analytical principles}

The guiding question of all analyses presented in this paper deals with what is done when technology workarounds occur in daily work practices. Three cases will be presented and explored. The first case shows how an explicit, professionally grounded decision to interact through human-to-human dialogue necessitates workarounds to deal with various organizational, traditionally standardized technologies used in adult psychiatric care. In the second case, diagnostic measures based on extensive narrative details must be provided outside the checkboxes of the new EPJ, and the third case provides an example of how patients' behavior in relation to communicating their illnesses impacts the way available technology is worked around in a geriatric ward. The three examples show how workarounds are both a collective and a political matter in different respects, and how the specificities of the various situations have different effects. Common to all three examples is that the way staff work around the new technology depends on how they practically encounter the particular conditions of each working situation. The professional judgment of staff is connected not only to the logic of the role of the new technology and its mediated administrative and economic logics in their work but also to the particularity of the situation, thus also making that judgment potentially innovative.

In all three empirical examples, the decisions regarding changes come from different places. In the case of the outreach adult psychiatric team, the team itself implemented the change initiative, for which reason their reflections about their desires for change were explicit and well-founded, and the changes described here contrast existing requirements and practices seen in more traditional institutionalized care. On the other hand, the situations arising from the staff workarounds in the psychiatric and geriatric hospital ward are interesting because the changes in work practice seem to be imposed on staff. The changes in these cases constitute overall structural changes entailing newtechnology decisions made elsewhere in the organization (Dupret \& Skov, 2016; Krogh, 2016), where the staff have little or no influence.

Although the conditions of change in the various organizational setups differ greatly, how professionals deal with institutionalized procedures and technological development is thought-provoking in the sense that, in both the psychiatric and geriatric fields, the decisions professionals take on how to provide quality care seem to remain 
tacitly innovative to management and to institutional culture. However, the examples provided are not meant to show a generalized way of working around technologies in health care, but rather to illustrate how invisible workarounds can be regarded as tacit innovation.

\section{Example I - Organizational change within the district psychiatric field}

A multidisciplinary psychiatric outreach team wanted to create a work practice where dialogue and respect rather than diagnostic symptoms and hierarchal positioning guided their decision-making processes. The Open Dialogue approach presented later in this paper is formulated as a means of meeting this aim.

The team delivers coordinative and consulting services, mainly through home visits in social psychiatric cohabitation houses or in patients' private homes. The conversations during home visits concern patients' treatment and well-being, in both medical and social terms, and might include social training (how to take the bus, how to do shopping, etc.). The team cooperates with other institutions and authorities that offer special training services, and it coordinates activities for patients. Patients temporarily hospitalized during periods of psychosis are visited by the case manager. Patient meetings are the team's core activity.

Before the Open Dialogue change process was initiated, the team usually approached their tasks in the way customary at hospitals, where documenting technologies like the EPJ structure the use of diagnostic symptoms and monitor staff visits, etc. Thus, morning conferences were held at which the psychiatrist would help delegate the day's tasks, such as who would be incoming patients' new case manager, or what kind of changes in treatment were required. Conversations about patients and the decisions made were based primarily on diagnostic measures and organized as one-to-one dialogues between the psychiatrist and the responsible case manager. When the Open Dialogue approach was implemented, these kinds of decision-making processes were not abandoned, however, but continued to exist alongside the new practices. Changing work practices was a demand. The staff began by establishing study group sessions in which they could talk informally about how they wanted to change their communication with and approach to patients, as they considered existing practice to be quite reductionist and alienating. The staff decided that one way of changing work practice was to introduce the Open Dialogue approach (Seikkula, 2000; Seikkula et al., 2001). This approach offered an apt way of introducing substantial organizational change because it dealt less with patient symptoms and more with the team's professional approach to organizing new ways of communicating what constitutes mental healthcare.

\section{The change initiative:The Open Dialogue approach}

The Open Dialogue approach is designed as a tool to renegotiate ways of professionalism and approaches to the patient (Seikkula, 2000; Seikkula et al., 2001)2. The approach is based on social-constructionist language theory (e.g., Gergen, 1985) and has a network-based approach inspired by systemic therapy (Selvini Palazzoli et al., 1980). However, the approach also contains the basic ideology of democracy and focuses on 
social relations and network as a prerequisite for mental health (Basaglia, 1971). These primary sources of inspiration give psychiatric staff the opportunity to work with an approach through which they can innovate and reorganize psychiatric care.

Open Dialogue revolves around seven principles: immediate help, dialogue, a social network perspective, responsibility, flexibility and mobility, psychological continuity, and tolerance of uncertainty (Seikkula, 2000; Seikkula et al., 2001). ${ }^{3}$ Each of these principles is the product of a larger argument, and they refer to a specific way of defining care and its organization as well as provide 'alternatives' to existing mental health organizational standards. ${ }^{4}$ Organizing such changes in work has consequences that affect how professionals monitor their activities, what arguments for treatment are viewed as valuable, how decisions are made, etc.

The outreach team's change initiative was driven by a wish to implement a new, alternative therapeutic approach that departed from traditional organizational setups the traditional high status of experts, the presence of hierarchy and dominant explanation models of psychiatric illness as originating from principally biological imbalances. The team's initiative can be seen as an instance of tacit innovation constructed via invisible struggles permeating the psychiatric organization's sociomaterial practices.

\section{Example II - New type of electronic patient journal in the psychiatric field}

A 'checkbox'-based EPJ has been implemented in the two eastern regions of Denmark in order to replace and synchronize outdated and incompatible IT systems in the health care system. This has heightened the degree of interactivity and real-time functions and, not least, led to a new way of documenting diagnostic decision-making processes on the basis of 'clicks' in checkboxes rather than of narrative descriptions. The update is aimed at making paper charts redundant in the delivery and management of patient care. The two regions employ 44,000 people in the health care sector, including doctors, nurses, secretaries, and other clinical and administrative staff, and an additional 9000 people in other nonhealth-related areas, all of which are affected by the significant changes imposed by the new technology. The organization, the working tasks, and professional roles have all changed (Krogh, 2016), and the new work procedures, in the psychiatric field in particular, have affected professionals' decision-making processes (Dupret, 2016). ${ }^{5}$ In professionals' experience, the new system has resulted in a doubling of medical prescriptions and prolonged the writing process, as doctors, not secretaries, now do the writing. During the implementation process, key professionals provided information on how to translate important clinical guidelines in the new system. However, professionals, particularly in the psychiatric field, say that the system fails to provide reliable, professional diagnostic measures, and that they have not had a substantial voice in developing the system.

\section{Example III - Technology use in a geriatric department}

The third empirical example is taken from the geriatric field, specifically one of 19 hospital wards visited as part of a larger research project on technological literacy (Hasse \& 
Brok, 2015, p. 342). Professionals were shadowed and interviewed on how they understand technology in their working life and how they experience and learn from its challenges. The research project did not differentiate between the various medical specialties and the ways technology played different roles in that respect. However, the use of technology in elderly care and treatment is special, as it is a professional practice that does not necessarily involve complex technology, although more so than in the psychiatric field. As in psychiatric practices, the geriatric department uses technologies designed for standardization, efficiency, and monitoring of care and treatment, including technologies such as diagnostic measures and EPJs. The geriatric department has more new technologies, however, than the psychiatric practice does. For instance, the nurses use a sphygmomanometer (electronically based blood pressure measurement), personal digital assistants (a little hand-held portable computer used extensively to record information about the treatment and condition of patients when meeting them face-to-face), electronic blood sugar measurement, etc. As such, the nurses in the geriatric department work with a lot of new digital technology. Professionals use these technologies in creative ways and demonstrate how apt they are at integrating them into sensitive caretaking (Dupret \& Rosenbæk, 2012) and ethical judgements (Krøjer \& Dupret, 2014). In other words, the use of technology is still an area where human-patient-technology relations are very much at stake and professionally negotiated. Thus, one could suggest that precisely these tacit innovative situations could be taken on board in the actual development of technologies.

\section{Analyses in psychiatric and geriatric settings}

\section{Analysis I - Organizational practices established through human interaction}

The first analysis is an example of an explicit, professionally grounded decision to interact through human-to-human dialogue instead of communicating through standardizing technologies. The workaround in this example results in a reconfiguration of the sociotechnical setup, where bodies rather than the standardizing technologies available become the important carriers of clinical knowledge.

The professionals working in the adult psychiatry field wanted to change their work practices. To this end, they decided to practice and discuss a new treatment approach and video-record these talks and practices for learning purposes (Dupret, 2010). As part of the research, the videos ended up becoming important ethnographic material, and what was performed in these videos became of great value in understanding how efforts to change the team's practices took place.

When watching the video of the study group, one notices that before beginning to talk, people move around a little, move their chairs, or shift places if there is an imbalance in the circle. (It appears to be possible to have one, but usually not two, empty chairs in the circle.) The moving around indicates that completing the circular form seems important. The placement of chairs in a circle makes bodies face the middle of the circle without facing any specific person. The circle appears to make any start or finish of speech random because no chair is designated for a leader, such as a chairperson.

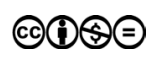


The placement of chairs in a circle, together with the absent table and the calm body language, seems to make the levelling of speech possible. The availability of speech that is not guided by hierarchical levelling, in other words that does not have one specific person who takes the lead, is also supported by the fact that neither the team manager nor the responsible consultant psychiatrist direct the speaking order or the topics covered, as is the case in chaired meetings with specified, written agendas (or patient lists, as in the morning conference).

Thus, we have the presences (the visible sociotechnical setup): the circle of chairs, the listening bodies in the circle, the circulation of conversation; and the absences (invisible sociotechnological setup), the technologies that have been removed from the group session: patient lists, agendas, calendars, mobile phones, questionnaires to fill out, and so forth. This sociotechnical setup helps the staff avoid determining the nature of the discussions. It allows the discussions to circle around such topics as the definition and purpose of the new treatment approach called Open Dialogue (e.g., Seikkula, 2002/2000), including topics like 'respect' and 'dialogue', and it allows anyone to decide upon the focus of the day. The important criterion of sustainability in this new practice is that the team must endeavor to refrain from making judgements or from giving each other direct advice in these sessions. For example, if a colleague expresses that she feels a relation with a patient is difficult, the other team members will not suggest ways of tackling the difficulty, but rather reflect upon what her story makes her think about. The absence of tables, the nonjudgemental, and nondecisive conversational form, the body language that is listening and 'open' engender a composition of participation that foregrounds human interaction.

Technologies affiliated with the team's daily practices are removed from the practice in the study group. The staff explains that these technologies inherently work against the team's ambition of working collectively and refraining from judgments and direct advice. For example, the electronic monitoring system is meant to show how big a caseload each professional has. A core element of practicing the new treatment approach is that, ideally, two professionals at a time should conduct the home visits. The monitoring technology does not support this practice; the activity can only be registered with one professional in the system. Thus, the team cannot register their activities in ways that conform with how they actually wish to do these visits, namely with two professionals at the time. This has resulted in workarounds where some visits have had to be monitored in alternative ways that do not 'exist' in the prescribed technology available. The monitoring technology, in fact, inhibited possible organizational change. The professionals' workaround reinforced the change. Likewise, their workarounds with the EPJ, meeting agendas, and other technologies while practicing the new treatment approach in the above study group setting are not a way of disregarding their patients or avoiding responsibility for their work. Neither do the workarounds indicate a lack of know-how regarding the use of the EPJ, etc. - on the contrary. The team seems very aware of the politics and logics inherent in the technologies they have at hand, and choose among them quite consciously when they want to develop new approaches to their patients in their work.

\section{Preliminary analytical conclusion}

The sociotechnical setup in the practicing of a new adult psychiatry treatment approach shows an alternative ordering of technology use. In the new practice, visibility is 
reversed. Things that are made visible and things that do not go against the practices of the rest of the organization. The EPJs, apparent hierarchical decision-making structures, and monitoring systems are made invisible, because how professional decisions are made and activities are monitored in the new work practice do not fit with the particular ideologies of the new treatment approach and its alternative ways of performing psychiatric health care. Human interaction and narratives are among the founding principles of the new practice - a practice maintained and reinforced through the staff creating alternative organizational setups despite the wider organization's available technologies.

\section{Analysis II - Professionalism outside clinical standards}

The second analysis will exemplify how one patient's out-of-standard behavior and another patient's out-of-standard condition of illness show how health care staff creatively handle a new and standardized 'checkbox' EPJ and saturation test (measurement of blood oxygen level). Workarounds here show how the use of standardizing new technologies conceived to streamline work practices for professionals, in fact, have the opposite effect, requiring explicit, new professional reflections, and actions that make clinical practice more time consuming and intricate. Both examples also illustrate how technologies mediate a specific scientific validation at times out of tune with how professionals judge a specific situation should be handled to enhance the quality of care. These new reflections and subsequent actions can potentially be considered as tacit innovation, as they ensure that patients receive ethically sound treatment despite the technologies available.

\section{Diagnostic measures cannot always be measured in standardized technologies}

In the psychiatric field, long narrative descriptions are used to formulate diagnostic measures. These are time-consuming, and technological development is aimed at addressing the particular apparent lack of efficiency in the health care sector (Krogh, 2016). However, existing EPJs allow for such long narrative descriptions.

A psychiatrist visited a young woman hospitalized for a month, during which she was diagnosed with schizophrenia. He expresses his frustration at having to reduce the argumentation for his diagnostic judgment to a list of symptoms clicked off in the checkboxes required by the new EPJ system. Narrative descriptions are possible in the old version of the EPJ. Not so with the new system.

The psychiatrist comes with an anecdote:

Imagine a doctor visiting a patient, having the journal at hand with a list of symptoms checked off and asking the patient: 'You have described derealisation (an officially recognized symptom of schizophrenia and an option to 'click' in the new journal, ed.). Tell me, how is it going with that?' The patient would ask what that means, and the psychiatrist would respond: 'Yes, I don't know, but it is written in your journal.' 
The psychiatrist continues to explain by comparing the newly implemented patient journal with the old one:

Patients totally follow you when you, as a psychiatrist, ask whether the patient is still experiencing dark shadows moving through the room, which matches with the description of the medical term 'hallucination' in the classic journal note.

The new EPJ based on the checkbox system seems to have profound professional consequences, especially in the psychiatric field. Relying on his professional judgment, the psychiatrist argues that patient narratives must be recorded in full detail for professional clinical judgment to be safe and qualified. The psychiatrist explains that, to provide his psychiatric patients with quality treatment, he still has to keep the old notes on a daily basis, thus resulting in invisible knowledge not recorded in the new journal format. As the diagnosis in the 'investigation period' can be subject to changes, it is important that colleagues have access to the unfiltered descriptions (and not just the list of symptoms), so the quality of the treatment also depends on double checking the interpretations of the narratives given by patients.

\section{Preliminary analytical conclusion}

The kind of professional judgment based on extended narrative details puts the politics of the standardizing, technologically mediated activities at stake. To sustain the health care system while also providing ethically sound care and treatment, doctors spend their time both complying with the new checkbox-based EPJ and doing the invisible work of providing extra information to colleagues that is not included in the EPJ.

\section{Analysis III - Invisibility is a matter of scientific legitimacy}

The third and last example is taken from an interview with a nurse, who points to how engaging with technologies is also a matter of what is recognized as valid knowledge in the organization and in health care in general - a specific scientific ideal.

The nurse explains a situation where he may consider how to use the standardized technologies:

We need an explanation for a given patient's tendency to fall. The patient's condition is often judged on the basis of a blood test rather than of the 'clinical picture' (i.e., observation of the patient), because people are particularly fond of the independent quantitative values. They are considered as more objective, because medical science is concerned with quantifiable measures. For newly graduated nurses these are a strong support in treatment/ clinical situations. And quantifiable goals are more difficult to argue against. With experience, you become more secure in your professional judgements.

As the above excerpt demonstrates, the nurse's professional judgment conducted by observing the patient (also called the clinical gaze within the nursing profession) is put 
aside in favor of doing extra blood tests. The blood tests are analyzed and provide quantifiable outputs used to make decisions on clinical treatment. The nurse suggests that this practice can be attributable to a widespread culture within health care organizations that portrays and institutionalizes 'independent, quantifiable measures' as more objective. He explains the prioritization of the extra blood testing as requiring 'fewer arguments' for the judgment of a given treatment. In the below excerpt, he recounts how certain organizational politics relate to the use of technologies - guidelines that force professionals to use the technologies, or at least make them difficult to work around. As in the previously described example regarding the psychiatrist's need to document the workaround by keeping old notes in addition to the new checkbox EPJ, in this instance, the professional judgment is forced to be based on specific blood tests, whereas in former professional practice, the patient would have been clinically judged on the basis of observations such as pale skin, etc.

The nurse:

We are compelled to measure certain vital values - blood pressure, saturations, etc. Different values give insight into the condition of the patient and thereby the necessity of treatment. Patients with lung problems and decreased circulation have cold fingers and toes. Then the SAT measurement cannot be done on a finger (measurement of saturation, ed.), because it will give a wrong output. You have to know that as a nurse. (...) The patient's judgement should override the SAT measurement in that case. If one is not aware of this, the consequence could be overtreatment with oxygen, for example. I cannot choose not to use the measure, but it should be put aside in certain situations. With dying patients, using the technology sometimes has no meaning. For example, in the case of fever it needs to be communicated that the patient has a fever. But I would choose not to take the patient's temperature (with a thermometer ed.), because to me it would be an instance of abuse to treat a dying patient. These choices require you to be professionally strong and able to stand firm in your decision.

A specific technology can be used to test blood pressure. However, at times, patients have chronically bad blood circulation, and tests using this technology can be misguiding. So, in addition to having professional reasons tied to what are acknowledged as valid measures (quantifiable measures coming from the technological output) to acquire certain blood test results, the nurse also explains that chronically ill bodies tend to have different organisms that are not compatible with the technology. Patient bodies and the legitimation of certain technologically based practices seem potentially to clash. Therefore, due to the bodily status of terminal and/or chronic patient bodies, they can be the reason why professionals work around the technology. When patients and technologies interact, their compatibility is not always in tune, because technologies cannot always adapt to changing bodies. Experienced professionals need to show sensible reasoning when determining what to do in this case.

\section{Preliminary analytical conclusion}

The presence of quantifiable measures that are transported and mediated through new technologies supports and stabilizes a specific form of binding commitment. In both the 
above examples, the professionals feel it is more difficult to argue against using the new technologies than to just use them in spite of the fact that both professionals have other professional arguments that are ethically and professionally driven.

Working around standardizing technology does not eliminate the need for professional documentation. In fact, the psychiatrist needs to stick to standard practice in order to maintain an ethical level of safety and quality in the treatment. The workaround results in a whole range of extra working procedures that are directly related to the patient's recovery, but not inscribed in the new technologies.

In both cases, standardizing new technology could potentially prevent the staff from acting on the urge to use their observational and communicative skills when making professional judgments. The fact that the use of many new technologies is compulsory leads professionals to focus on those technologies in their professional judgments and activities. This raises the question of how organizations can maintain a climate of trust regarding professional judgment in situations where staff work around standardized technologies. Both using technology and working around it require not only knowledge in its use but also an ability to navigate between the necessary and ethical aspects that ensure it will be used sensibly, as well as an ability to prioritize between using the technology for the sake of the system and the organization and using it for the sake of the patient.

\section{Conclusion}

The ethnographic material in this paper illustrates how technologies can be used in unforeseen ways when put in actual use by frontline staff members, thus underlining the need to build bridges between technology producers and technology end-users (cf. McNeill, 2013).

The question remains whether the available tools and the various kinds of participative and collaborative methods can live up to the expectations of creating more sustainable and smoothly operating organizations. As illustrated by the examples in this paper, health care professionals in a particular workplace will typically face a number of external expectations, that is, from management, from IT systems implemented from above, etc. Although the Danish health care system remains highly complex internally and relatively fragmented, it has a tradition for top-down management (Hjortshøj, 2016), as well as being subject to funding issues, with both politicians and managers navigating within a basic paradigm of efficiency and rationalization. Health care professionals' unions have been criticizing the NPM regime with its focus on measurability and control systems for years (Wiese, 2016), while also calling for a say in the implementation of new technologies. The Danish physicians' union has explicitly called for the more systematic use of participatory design methods (Lægeforeningen, 2012). Still, the methods in use seem to impede a thorough discussion of the basic premises of the health care system as such, one that fully involves and acknowledges all stakeholders - whether organizationally or in relation to the development and implementation of new technologies. Thus, workarounds performed by health care professionals will continue to exist as tacit innovation, rather than being facilitated and even encouraged as explicit innovation of potentially crucial importance to the health care field. 


\section{Working around technologies}

Exploring how end-users actually use technologies provides critical insight into the official purpose of rationalization and efficiency. The concept of invisibility becomes important in this respect, as it underlines how new technology workarounds can influence organizational sustainability and development and exposes an aspect of technology use that adds to its already acknowledged function toward standardization and efficiency.

Technology workarounds do not necessarily imply technological shortcomings or professional incompetence - quite the opposite. The technology workarounds shown in this paper provide important insights into how health care technologies seem at times to make professionals' ability to handle the complexity of health care practices invisible. It is not that these technologies in themselves have no important role to play in the sustainability and efficiency of high standard health care, but in some situations, workarounds can consist of new innovative practices that should be acknowledged as such, and they can be a paramount sign of ethically based professional competency and organizational success. Potentially, the critical practice among health care professionals offers crucial insights into health care and creates possibilities for rearranging it through bottom-up processes and the systematic involvement of all stakeholders. An important step in this direction could be to fully acknowledge health care professionals as potential co-creators rather than merely end-users of technologies - individuals at once drawing on and developing the array of already existing methodologies aimed explicitly at crossdisciplinary innovation.

This paper has shown that different types of technology workarounds rely on different types of human-technology interactions in work-life situations. Some examples can be connected to clinical experience, but at the same time coupled with in-depth knowledge about what a technology can or should be able to do. In conclusion, one can point to different types of workarounds that seem to result in invisible work in the workplace:

1. Workarounds that happen with the aim of protecting a specific practice from being influenced by the surrounding technology-driven practices of the organization.

2. Workarounds that happen when diagnostic measures are not attuned with the requirements of the technology and vice versa.

3. Workarounds that happen on the basis of moral judgments other than those embedded in the technology.

In all three examples, professionals seem to have difficulty making their work with workarounds visible in the organizations where they work. At the same time, however, professionals involved in the situations presented explicitly choose to conduct their work practices in ways that diverge from those prescribed by their workplace.

Although at times professionals provide organizational, ethical, and technical arguments against using technologies, they still seem to have to do double work in the sense that they have to do twice the amount of work. For example, they give sensible grounds for not using an available technology or for doing activities both with and without a technology. On the one hand, this not only points to the creativity and innovation of health care professionals, but also to the fact that heavy, legitimizing politics are inscribed in the organizational introduction of new technologies - politics that IT professionals may or may not reinforce when developing these technologies. Technologies

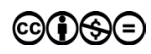


seem to be able to put aside professional judgments and overrule specific kinds of local practices - which underlines the need for critical reflection that goes beyond the merely instrumental part of the processes.

This leaves us with questions regarding how workarounds spur new debates about how organizations can leave more room for changes that are ideologically or professionally based. If professionals argue that health care is made more meaningful by using technologies other than those currently provided for, how is it possible to cooperate with IT staff and thus develop sustainable health care practices? Despite the already existing methods, this cooperation seems potentially conflictual, as IT staff are usually called for when management wishes to change existing practices by developing and implementing the use of standardized technologies. Although the wide range of new, inclusive methodologies help tech staff reach out to, for example, health care staff, organizations still need participatory design methods, hackathons, etc., to realize the possibility of democratizing innovative design processes (Verbeek, 2006) and potentially give staff the right to challenge the existing normativity imbedded in the development of technologies. However, using these methods in health care settings while also addressing the normativity and politics imbedded in the technologies can pave the way for acknowledging professionals' contributions as explicit innovation and break down the barriers between technology developers and end-users.

\section{What is tacit innovation?}

In contrast to a more traditional reading of the field of innovation and mental health, this paper does not take a linear, accumulative, or causal approach to innovation. Rather, it argues in favor of adding the concept of invisibility to the body of research on innovation in working life studies. Tacit innovation is about recognizing invisibility. It is a way of redefining what is acknowledged as innovation, and a way of recognizing innovation that engenders new ways of knowing and performing work practices.

The various workaround strategies among professionals show an aspect of technology use that adds to the already acknowledged technological functions of standardization and efficiency. When professionals work around technologies, workplaces become recognizable as something other than merely abstract systems. Here, tacit innovation can also be called 'the human face of the workplace'. When professionals attempt to change their work practices in spite of technological standards and requirements, their endeavors should not automatically be regarded as mere resistance to change, but as a very important aspect of generally simplifying their work and making it go more smoothly on the basis of professional insight. These conclusions point in part to professionals' creativity and innovation, but they also indicate that legitimizing normativity is inscribed in the organizational introduction of technologies.

\section{References}

Alcadipani, R. and J. Hassard (2010) Actor-Network Theory, organizations and critique: towards a politics of organizing. Organization 17(4), 419-435. DOI: http://dx.doi. org/10.1177/1350508410364441 
Ash, J.S., Berg, M. and Coiera, E. (2004), Some unintended consequences of information technology in health care: The nature of patient care information system-related errors, Journal of the American Medical Informatics Association 11(2): 104-112.

Barley, S. and Kunda, G. (2001), Bringing Work Back In, Organization Science 12(1): 76-95. DOI: https://doi.org/10.1287/orsc.12.1.76.10122.

Basaglia, F. (1971) L'instituzione negata. In Swedish Ned med den instituionella psykiatrin. Stockholm, Sweden: PAN/Nordstedt.

Beck, K., Beedle, M., Bennekum, A., Cockburn, A., Cunningham, W., Fowler, M., Grenning, J., Highsmith, J., Hunt, A., Jeffries, R., Kern, J., Marick, B., Martin, R., Mellor, S., Schwaber, K., Sutherland, J. and Thomas, D. (2001), Manifesto for Agile Software Development. [online] http://www.agilemanifesto.org/.

Berg, M. and Mol, A. (eds.) (1998), Differences in medicine - Unravelling practices, techniques, and bodies, Duke, Durham. DOI: https://doi.org/10.1525/maq.1999.13.4.508.

Brown, J.S. and Duguid, P. (1991), Organizational Learning and Communities-of-Practice: Toward a Unified View of Working, Learning, and Innovation, Organization Science 2(1): 40-57. DOI: https://doi.org/10.1287/orsc.2.1.40.

Callon, M. (1986), Some elements of a sociology of translation: Domestication of the scallops and the fishermen of St Brieuc Bay. In J. Law (ed.), Power, action and belief (pp. 196-233). Routledge Kegan Paul,London. DOI: https://doi.org/10.1111/j.1467-954X.1984.tb00113.x

Dupret, K. (2010), Innovating mental health care, a configurative case study in intangible, incoherent and multiple efforts, Ph.D. dissertation. Danish School of Education, Arhus University: Århus

Dupret, K. and C. Hasse (eds.) (2012), Teknologiforståelse på skoler og hospitaler [Technological literacy - In schools and hospitals]. Århus Universitetsforlag: Århus

Dupret K. and P. Rosenbæk (2012), Distribueret professionel sensitivitet i teknologianvendelse [Distributred professional sensitivity in technology use]. In Dupret, K. and C. Hasse (eds.), Teknologiforståelse på skoler og hospitaler [Technological literacy - In schools and hospitals]. Århus Universitetsforlag: Århus

Dupret, K. and Skov, H. (2015) Komplekse veje [Complex ways], in C. Hasse, and L. S. Brok (ed.), TekU modellen: Teknologiforståelse i professionerne. [The TecU model: Technological literacy in professional work]. (Copenhagen: U Press), 83-112.

Dupret, K. (2016), Conversations with health care staff in relation to pilot study investigating the implementation of EPIC electronic patient journal in Denmark. Unpublished paper.

Feldman, M., and Pentland, B. (2003), Reconceptualizing Organizational Routines as a Source of Flexibility and Change. Administrative Science Quarterly, 48(1): 94-118. DOI: https://doi.org/10.2307/3556620.

Ferreira, FK., Song, EH., Gomes, H. Garcia, EB. and Ferreria, LM. (2015), New mindset in scientific method in the health field: Design Thinking. Clinics, [online] 70(12): 770-772. DOI: https://doi.org/10.6061/clinics/2015(12)01.

Gergen, K. (1985) The social constructionist movement in modern psychology. American Psychologist, 40, 266-275. DOI: http://dx.doi.org/10.1037/0003-066X.40.3.266

Greimas, A. (1987) On meaning, selected writings in semiotic theory. Minneapolis, MN: University of Minnesota Press.

Gulla, J. (2012), Seven Reasons IT Projects Fail, IBM Systems Magazine, [online]. http://ibmsystemsmag.com/power/systems-management/workload-management/project_pitfalls/

Halbesleben, J.R., D.S. Wakefield and B.J. Wakefield (2008), Work-arounds in health care settings: literature review and research agenda. Health Care Management Review, 33(1): $2-12$.

Haraway, D. (1991), A Cyborg Manifesto: Science, Technology, and Socialist-Feminism in the Late Twentieth Century. Simians, Cyborgs and Women: The Reinvention of Nature, 149-181. Routledge, New York. 
Hasse, C. and L. Brok (eds.) (2015), TekU-Modellen - Teknologiforståelse i professionerne. [The TechU-model - Technological literacy in the professions] Copenhagen: Upress

Hirschhorn, L. (1984), Beyond mechanization, work and technology in a postindustrial age. Cambridge, Mass: MIT.

Hjortshøj, A. (2016), Brugercentreret innovation - når en metode til udvikling introduceres $i$ sundhedsvosenet. [User driven innovation - when a developmental method is introduced in the Health Sector]. Master Thesis in Public Governance. CBS

Høyrup, S. (2010), Employee-driven innovation and workplace learning: basic concepts, approaches and themes. Transfer: European Review of Labour and Research, 16(2): 143-154. DOI: https://doi.org/10.1177/1024258910364102.

Høyrup, S. og KL. Andersen (2012), Teknologiforståelse, organization og medarbejderdreven innovation i sygeplejearbejdet. [Technological literacy, organization and userdriven innovation in nursing]. In Dupret, K., and Hasse, C. (eds.) Teknologiforståelse - på skoler og hospitaler [Technological literacy - in schools and hospitals]. Aarhus: Aarhus Universitetsforlag.

Huniche, L. and F. Olesen (2014), Teknologi i Sundhedspraksis. [Technology in health practices]. Copenhagen: Munksgaard

Koivisto, J., Pohjola, P., and Pitkänen, N. (2015), Systemic Innovation Model Translated into Public Sector Innovation Practice. The Innovation Journal, 20(1): 2-17.

Krogh, S. (2016), Anticipating organizational change, a study of the pre-implementation phase of Sundhedsplatformen, PhD Thesis. Copenhagen: PhD School of Economics and Management.

Krøjer, J., and Dupret, K. (2014), Moral Literacy in Technological Care Work. Ethics and Social Welfare, 1-14. DOI: http://dx.doi.org/10.1080/17496535.2014.938672.

Kyng, M. and Faber, L. (2002), Sundheds-it og velfardsteknologi. Den sunde balance mellem hurtige resultater og langsigtede løsninger. [Health-IT and welfare technology. The healthy balance between quick results and long term solutions] Aarhus, Denmark: Caretech Innovation. https://alexandra.dk/sites/default/files/downloads/Caretech_Aarsrapport-2012. pdf

Kyng, M., Ballegaard, SA, Hansen, TR, (2008), Healthcare in Everyday Life - Designing Healthcare Services for Daily Life. SIGCHI Conference on Human Factors in Computing Systems. City: Florence, Italy: ACM: 1807-1816. https://pdfs.semanticscholar. org/6ea9/38df789e3386c9194883323582b4ce7dafea.pdf DOI: https://doi.org/10.1145/ 1357054.1357336.

Kyng, M. (2015), On Creating and Sustaining Alternatives: The case of Danish Telehealth. Aarhus Series on Human Centered Computing, 1(1). DOI: https://doi.org/10.7146/aahcc. v1i1.21297.

Latour, B. (2005), Reassembling the Social - An Introduction to Actor-Network-Theory. Oxford University Press, New York. DOI: https://doi.org/10.1080/10967490701515606.

Latour, B. (1996), On actor-network theory - A few clarifications. Soziale Welt, 47 (4): 369-381

Latour, B. (1993/1991), We have never been modern. Harvard University Press, Cambridge, Mass.

Latour, B., and Woolgar, S. (1986/1979), Laboratory Life - The construction of Scientific Facts. Princeton University Press, USA.

Lægeforeningen (2012), It på sundhedsvosenets betingelser. Lageforeningens sundheds-it-politik. Copenhagen: Lægeforeningen, 2-3. https:/www.laeger.dk/sites/default/ files/lf it paa sundhedsvaesenets betingelser.pdf.

Lehn-Christiansen, S. (2016), Tvoerprofessionelt samarbejde $i$ sundhedsfaglig praksis. [Cross-professional work in health practices]. Munksgaard: Copenhagen

Levy, S. (1984), Hackers: Heroes of the Computer Revolution. Garden City, N.Y.: Anchor Press/Doubleday. 
McNeill, M. (2013), 7 Benefits of Agile and User Centred Design. [online] Thoughtworks. https://www.thoughtworks.com/insights/blog/agile-and-user-centered-design

Mol, A. (2002), The body multiple. Duke University Press. Durham. DOI: https://doi. org/10.1017/S174585520722558X.

Moser, I. (2003), Road Traffic accidents. Phd thesis. Oslo University Press: Oslo.

Oudshoorn N. (2008) 'Diagnosis at a distance: the invisible work of patients and health care professionals in cardiac telemonitoring technology', Sociology of Health and Illness 30, 272-288. DOI: http://dx.doi.org/10.1111/j.1467-9566.2007.01032.x

PMI (2017), Success Rates Rise. Transforming the high cost of low performance, 9th Global Project Management Survey. [online] Philadelphia: Project Management Institute: 2-8. https://www.pmi.org/-/media/pmi/documents/public/pdf/learning/thought-leadership/ pulse/pulse-of-the-profession-2017.pdf.

Pols, J. (2006), Accounting and Washing: Good Care in Long-Term Psychiatry. Science, technology and human values, 31(4): 409-430. DOI: https://doi.org/10.1177/0162243906287544.

Rankin, J., and Campbell, M. (2006), Managing to nurse - Inside Canada's Health care reform, University of Toronto Press, Toronto

Raymond, Eric (1999), The Cathedral and the Bazaar: Musings on Linux and Open Source by an Accidental Revolutionary, Sebastopol, CA: O'Reilly \& Associates

Schumpeter, J.A., 1934 (2008) The Theory of Economic Development: An Inquiry into Profits, Capital, Credit, Interest and the Business Cycle, translated from the German by Redvers Opie, New Brunswick (U.S.A) and London (U.K.): Transaction Publishers.

Seikkula (2000), Åpne samtaler [Open Dialogue]. Helsingfors: Tano Ashehoug.

Seikkula, J., Alakare, B., and Aaltonen, J. (2001), Open dialogue in psychosis I: An introduction and case illustration. Journal of Constructivist Psychology, 14(4): 247-265. DOI: http://dx.doi.org/10.1080/107205301750433397.

Selvini Palazzoli, M., Boscolo, L., Cecchin, G., \& Prata, G. (1980) Hypothesizing - circularity - neutrality: Three guidelines for the conductor of the session. Family Process, 19, 3-12. DOI: http://dx.doi.org/10.1111/j.1545-5300.1980.00003.x

Simonsen, J., Scheuer, J. D., and Hertzum, M. (2015), Accreditation and participatory design in the healthcare sector. In A. Öörni, N. Iivari, K. Kuutti, H. Oinas-Kukkonen, and M. Rajanen (Eds.), IRIS38: Proceedings of the 38th Information Systems Research Seminar in Scandinavia Oulu, Finland: University of Oulu.

Silver, JK., Binder, DS., Zubcevik, N. and Zafonte, RD. (2016), Healthcare Hackathons Provide Educational and Innovation Opportunities: A Case Study and Best Practice Recommendations. Journal of Medical Systems (40), 177. DOI: https://doi.org/10.1007/s10916016-0532-3.

Star, S. L. (1991), Power, technology and the phenomenology of conventions: on being allergic to onions. In Law, J. (ed.). A Sociology of Monsters - essays on power, technology and domination (pp. 26-56). London, UK: Routledge. DOI: https://doi.org/10.1111/j.1467954X.1990.tb03347.x.

Star, S.L. and Strauss, A. (1999), Layers of Silence, Arenas of Voice: The Ecology of Visible and Invisible Work. Computer Supported Cooperative Work 8: 9-30. DOI: https://doi. org/10.1023/A:1008651105359.

Verbeek, P. (2006), Materializing Morality - Design Ethics and Technological Mediation. Science, Technology and Human Values 31(3): 361-380. DOI: https://doi. org/10.1177/0162243905285847.

Wiese, Trine (2016), Et sygehus er ikke en fabrik [A hospital is not a factory], Sygeplejersken $1: 18-22$ 


\section{End notes}

1 At the time, the team had a caseload of approximately 100 patients. The average caseload per case manager in the team was around 20 patients.

2 Also called the 'Lapland model' due to its geographical place of origin. Furthermore, we deliberately use the term 'approach' and not 'treatment' or 'model', because they connote alliances with a medical worldview. The use of Open Dialogue in this team is very much about finding an alternative to that form of healthcare.

3 The Open Dialogue approach has its roots in northern Lapland. It took off in the mid-1980s with a wish to develop an alternative to existing psychiatric practices (Andersen in Seikkula, 2000, p. 9). At the beginning of the 1980 s, the psychologist Jaakko Seikkula and consultant psychiatrist Jyrki Keränen became responsible for the emergency psychiatric service and later for all psychiatric services in western Lapland, an area with 72,000 inhabitants. Later, they also moved network meetings into patients' homes. They changed the way the meetings were conducted and, with time, more families wished to participate in the treatment meetings.

4 The international literature refers in more detail to the seven main principles (Seikkula, 2000; Seikkula et al., 2001).

${ }_{5}$ https://www.psykiatri-regionh.dk/undersoegelse-og-behandling/Sundhedsplatformen/Sider/default.aspx 